\title{
Physiological Effects of Power Fitness Yoga Course in Community University 社區大學強力適能瑜珈課程之生理效應
}

\author{
Kuei Hui CHAN ${ }^{1}$ Ya-Hsin HSIAO ${ }^{2}$ Chean-Chean HUANG $^{2}$ \\ ${ }^{1}$ Graduate Institute of Coaching Science, National Taiwan Sport University, \\ Taoyuan, TAIWAN \\ ${ }^{2}$ Department of Sport and Business Management, \\ Da-Yeh University, Changhua, TAIWAN
}

\author{
詹貴惠 ${ }^{1} \quad$ 蕭雅馨 ${ }^{2} \quad$ 黃娟娟 ${ }^{2}$ \\ ${ }^{1}$ 台灣桃園體育大學教練研究所 \\ ${ }^{2}$ 台灣彰化大葉大學休閒事業管理學系
}

\begin{abstract}
The purpose of this study was to investigate the effects of the power fitness yoga course of Community University intervention on basic physiological parameters, anthropometric parameters as well as muscular and cardiopulmonary fitness. Fifteen females were participated this study. Subjects took a 90-minutes power fitness yoga course once a week for 12 weeks. The resting heart rate, blood pressure, body weight, body fat percentage, waist-to-hip ratio, body mass index, back strength, sit-up test as well as 3-minutes step test of subjects were tested before and after the course. Paired t-tests were used to compare the variables. The results showed that after 12 weeks of power fitness yoga course, the resting heart rate, diastolic pressure, body fat percentage and waist-to-hip ratio had significant decreased. The cardiopulmonary index of 3-minutes step test was significantly increased. There were no differences on the other variables ( $>$.05). The results indicate that 12-week power fitness yoga course in Community University can improve the resting heart rate, diastolic pressure, waistto-hip ratio and body fat percentage as well as promote cardiovascular fitness.
\end{abstract}

Keywords: power fitness yoga, body fat percentage, waist-to-hip ratio, muscular fitness, cardiopulmonary fitness.

\section{摘 要}

本研究旨在探討社區大學之強力適能瑜珈課程對基礎生理值、體位值、肌肉及心肺適能等生理值的影響。研究以15名女性學 員為對象, 進行為期 12 週的研究, 研究期間受試者在老師的指導下每週從事一次 90 分鐘的強力適能瑜珈運動。在實驗前、後均測 量受試者之安靜心跳率、血壓、體重、體脂率、腰腎比、身體質量指數、背肌力、1分鐘屈膝仰臥起坐及體力指數, 並以相依樣 本 $\mathrm{t}$ 考驗比較前、後測各項數值之差異。結果顯示: 經過 12 週的課程後, 受試者之安靜心跳率、舒張壓、體脂率與腰慰比均顯著 下降, 且體力指數有顯著之提升, 其他數值則無差異。本研究結果證實社區大學所開設之強力適能瑜珈課程能有效降低安静心跳 率、舒張壓、腰慰比與體脂率, 並提升心肺適能。

關鍵詞：強力適能瑜珈、體脂率、腰慰比、肌肉適能、心肺適能 


\section{壹、緒論}

人口老化是現代社會普遍的現象，隨著年齡的增加， 伴隨而來的常是慢性疾病; 藉由運動改善體適能是減少慢 性疾病發生的方式之一。在眾多運動中, 瑜珈（yoga）近 來逐漸成為各地流行的健康風潮。美國時代雜誌在2001年 曾以瑜伽做為封面, 大篇幅介紹席捲全美大陸的這股健康 風潮（林貞岑, 2003）。瑜珈有許多派別, 其中哈達瑜珈

(Hatha yoga) 為最古老, 也是最普遍的瑜珈, 許多與瑜珈 相關的研究都以此為訓練課程; Goldberg (1997) 指出: 因 健康因素而從事瑜珈訓 者有 $98 \%$ 表示瑜珈對健康是有助益 的。瑜珈的益處可由生理與心理兩個層面顯現, 生理效應包 括：健康體適能之促進、神經內分泌系統之平衡、生理放鬆

(減少肌肉緊張、降低心跳、血壓等); 心理效應則為穩定 自律神經、減少壓力與消除精神緊張, 達到心靈安定、情緒 增進的效果 (洪睿聲、陳坤䫅, 2003) 。研究顯示哈達瑜珈 可改善安靜心跳率、血壓、腰圍、心肺適能、肌肉適能與柔 軟度 (Bharshankar, Bharshankar, Deshpande, Kaore, and Gosavi, 2003 ; Madanmohan, Udupa, Bhavanani, Shatapathy \& Sahai, 2004; Tran, Holly, Lashbrook, \& Amsterdam，2001；陳金鼓與甘光熙，1997；陳金鼓，2000；呂 碧琴，1997），同時亦具有降低血脂質、血壓、血糖及改變 體內的荷爾蒙及抗氧化能力之效果 (Innes, Bourguignon, \& Taylor, 2005)。

然而, 瑜珈一詞常與神祕、高難度畫上等號, 使許多國 人望之怯步（朱碧梧，2003），因此一些瑜珈愛好者將早期 的瑜珈作調整, 以吸引更多人參與。從1990年代開始, 美國 地區逐漸發展出瑜珈體位（Yoga Asana）及體適能兼具的 強力瑜珈（power yoga）, 從身體的柔軟度及肌力同時並重 練習, 以避免各關節及愺帶因過度伸展而造成傷害。一位具 有國際健身教練資格的陸文澒教練於1998年將此風潮帶入台 灣, 發展出『強力適能瑜珈 ( power fitness yoga)』。強 力適能瑜珈乃以哈達瑜珈的姿勢為基礎, 融合肌力、肌耐力 概念的姿勢、動作，並䪿取艾英加瑜功（Iyengar yoga）、 皮拉提斯瑜珈（Pilates yoga）與阿斯唐伽瑜珈（Astanga yoga）之動作概念, 再融入現代的運動醫學理論, 發展而來 的。其乃利用身體自主的力量來運動, 將一連串設計好的動 作流暢组合起來, 再配合強而有力的呼吸, 使身體充滿熱能 （陸文䫏、支藝樺，2001）。中華民國有氧體能運動協會曾 舉辦『強力適能瑜珈師資班』, 以推廣強力適能瑜珈, 之後 許多健身俱樂部及社區大學也紛紛開設此課程。
目前與強力適能瑜珈相關的文獻並不多, 其中朱碧梧 （2003）的文章主要是介紹強力適能瑜珈在體育教學的應 用, 同時提到體育課興趣選項的大學生參與強力適能瑜珈課 程後，1分鐘仰卧起坐平均進步了 2.5 次（提升 $9.8 \%$ ）、坐姿 體前彎平均進步了 4.1 公分 (提升 $15.4 \%$ ) ; 另有二篇研究探 討持續從事強力適能瑜珈的生理效果。溫蕙甄、蔡昆霖、陳 雅慧與方進隆（2005）以35位無運動習慣的停經後婦女為對 象, 進行每週3次、每次 1 小時（包含：30分鐘之強力適能瑜 珈、20分鐘肌力訓練及 10 分鐘之緩和伸展放鬆）、12週的強 力適能瑜珈運動課程（另以22位為控制組），結果顯示12週 的課程後受試者的身體質量指數、屈膝仰卧起坐及6 分鐘走 等體適能皆有顯著改善。此外, 鄒碧鶴與黃偁如（2005）以 58位四技學生為對象，實施每週3次、每次 1 小時（包含：5 分鐘功能暖身、 30 分鐘強力適能瑜珈、15分鐘復健矯治操、 5 分鐘呼吸練習及5 分鐘靜坐冥想) 、持續 14 週的適能瑜珈課 程, 結果顯示受試者之身體質量指數、心肺適能、腹肌耐 力、柔軟度、下肢肌力、收縮壓、舒張壓和安靜心跳率均有 顯著效果。這些研究顯示每週3次、每次 1 小時強力適能瑜珈 課程對身體質量指數、體適能、心跳及血壓均有所助益。

運動對健康的益處是眾所皆知的, 但在現今繁忙的社會 中, 每週3次、每次 30 分鐘 1小時的運動對許多上班族婦女 而言是非常困難的, 因此許多社區大學開立每週一次的課程 運動課程以鼓勵社會大眾參與運動。台中市之社區大學每年 開辦三期、每期 3 個月, 每週上課一次, 而這樣的課程規劃 是否能有健康上的助益為本研究所欲探討的問題。故本研究 旨在探討社區大學的強力適能瑜珈課程（每週1次、每次 90 分鐘、為期 12 週）對參與者之基礎生理值、體位值、肌肉及 心肺適能之效益, 期能作為未來社區大學開課及其他推廣者 之參考。

\section{武、研究方法}

\section{一、研究對象}

本研究以台中市大墩社區大學之強力適能瑜珈課程班的 女性學員為對象, 平日均無固定之運動習慣。實驗之初共 16 名學員參與本計劃, 全程參與的學員共 15 位, 其基本資料如 表一。

\section{表一 受試者基本資料}

\begin{tabular}{|c|c|c|c|c|}
\hline 變項 & Mean $=$ & $\pm \mathrm{SD}$ & 最大值 & 最小值 \\
\hline 年齡（歲） & 38.0 & $\pm \quad 8.9$ & 53.0 & 24.0 \\
\hline 身高 (公分) & 161.2 & $\pm \quad 3.5$ & 167.0 & 155.0 \\
\hline 體重（公斤） & 56.2 & \pm 9.7 & 85.8 & 47.6 \\
\hline
\end{tabular}




\section{二、實驗步驟與方法}

1. 受試者先填寫個人資料、健康狀況調查表、個人疾病 史及受試者同意書。實驗之初先測量受試者之基礎生 理值（安静心跳率及血壓）、體位值（anthropometric parameter；包括：腰慰圍、身體質量指數及體脂率）與 肌肉及心肺適能 (肌力、肌耐力及心肺耐力) 等數值。

2. 前測完成後, 在老師的帶領下每週進行 1 次 (每次90分 鐘）的強力適能瑜珈課程（除上課時間外並未自行練 習），12週後再次測量前述之各項數值。

3. 強力適能瑜珈課程內容

本研究指導強力適能瑜珈者為具有美國YMCA體適能呚 官證照之大學體育教師, 並經強力適能瑜珈師資班認 證合格, 平日亦擔任台中YMCA之強力適能瑜珈課程敉 學。

每次強力適能瑜功課程均包含暖身、主要課程動作、功 能性瑜珈操及伸展緩和動作四個部分, 全程共計 90 分 鐘；12週的課程內容如表二。本研究進行期間曾以無線 心跳記錄器紀錄部分受試者從事 90 分鐘強力適能瑜加運 動時的心跳率, 以評量運動強度; 估計本研究的強力適 能瑜珈訓練之運動強度為最大心跳率的 $66 \%$ $85 \%$ 。

4. 基礎生理值與體位值測量

受試者經隔夜空腹後至實驗室先靜坐休息 10 分鐘, 以電 子血壓計（Terumo ES-P2000，Japan）測量心跳率、 血壓, 之後測量身高、體重, 並以生物電阻脂肪分析 儀（Biodynamics 450, Japan）測量體脂率; 再以測 量所得之身高與體重換算身體質量指數 (body mass index；計算公式為：體重 $\div$ 身高 2 ; 單位為 $\mathrm{kg} / \mathrm{m} 2)$ 。 另外, 以軟尺測量腹部寬度最小處之腰圍與慰部最大周 徑之臀圍。
5. 肌力及心肺耐力測量

受試者於餐後1小時以電子式背肌力計（TKK 5402 , Japan）測量背肌力（代表全身的肌力），測量時令受 試者直立於背肌力計的踏板上, 上身前傾約 $30^{\circ}$, 兩膝 伸直, 將把手調整至膝蓋高度, 之後用力伸直軀幹上 拉把手, 重複測量三次取最大值。另依教育部（1997） 所公告之方法測量 1 分鐘屈膝仰臥起坐（代表腹部肌耐 力）及3分鐘登階測驗（代表心肺耐力, 以體力指數表 示之）。

\section{三、資料處理}

1. 所有數值以平均數士標準差 (Mean $\pm \mathrm{SD})$ 表示。

2. 以相依樣本 $\mathrm{t}$ 考驗（paired t-test）比較課程介入前、後 之基礎生理值、體位值、肌力及心肺適能等之差異。

3. 統計之顯著水準訂為 $\alpha=.05$ 。 


\section{表二 12 週之強力適能瑜珈課程內容}

\begin{tabular}{|c|c|c|c|c|}
\hline 週次 & $\begin{array}{l}\text { 暖身 } \\
(15 \text { 分鐘 })\end{array}$ & $\begin{array}{l}\text { 主要課程動作 } \\
(40 \text { 分鐘 })\end{array}$ & $\begin{array}{c}\text { 功能性瑜功操 } \\
(20 \text { 分鐘 })\end{array}$ & $\begin{array}{l}\text { 伸展緩和動作 } \\
\text { (15分鐘 })\end{array}$ \\
\hline 1 & $\begin{array}{l}\text { 氣功暖身十式、功 } \\
\text { 能有氧操五式 }\end{array}$ & $\begin{array}{l}\text { 站立平衡式 : 基本站姿平 } \\
\text { 衡各式、大樹式 }\end{array}$ & $\begin{array}{l}\text { 背部強化操五式、腹部功能 } \\
\text { 操四式、兔式 }\end{array}$ & $\begin{array}{l}\text { 下背伸展操五式、 } \\
\text { 大休息式 }\end{array}$ \\
\hline 2 & $\begin{array}{l}\text { 氣功暖身十式、功 } \\
\text { 能有氧操五式 }\end{array}$ & 拜日式: 簡式、蛇式 & $\begin{array}{l}\text { 背部強化操五式、腹部功能 } \\
\text { 操四式、鵒式、兔式 }\end{array}$ & $\begin{array}{l}\text { 下背伸展操五式、 } \\
\text { 大休息式 }\end{array}$ \\
\hline 3 & $\begin{array}{l}\text { 氣功暖身十式、功 } \\
\text { 能有氧操五式 }\end{array}$ & $\begin{array}{l}\text { 站立三角式 : 大側角伸展 } \\
\text { 式、三角支撐式 (屈腿、 } \\
\text { 伸腿) }\end{array}$ & $\begin{array}{l}\text { 平板拉腿式、背部強化操五 } \\
\text { 式 }\end{array}$ & $\begin{array}{l}\text { 下背伸展操五式、 } \\
\text { 大休息式 }\end{array}$ \\
\hline 4 & $\begin{array}{l}\text { 氣功暖身十式、功 } \\
\text { 能有氧操五式 }\end{array}$ & $\begin{array}{l}\text { 擴胸伸背式、連續犬式脊 } \\
\text { 椎操＋支撐式 }\end{array}$ & $\begin{array}{l}\text { 平板拉腿式及抬腿式、橋式 } \\
\text { 脊椎操、蛙式 }\end{array}$ & $\begin{array}{l}\text { 下背伸展操五式、 } \\
\text { 大休息式 }\end{array}$ \\
\hline 5 & $\begin{array}{l}\text { 氣功暖身十式、功 } \\
\text { 能有氧操五式 }\end{array}$ & $\begin{array}{l}\text { 站立平衡式 : 基本站姿平 } \\
\text { 衡各式・大樹式、鶴姿、 } \\
\text { 老鷹姿 }\end{array}$ & $\begin{array}{l}\text { 背部強化操五式腹部功能操 } \\
\text { 四式.魚式 }\end{array}$ & $\begin{array}{l}\text { 下背伸展操五式、 } \\
\text { 大休息式 }\end{array}$ \\
\hline 6 & $\begin{array}{l}\text { 氣功暖身十式、功 } \\
\text { 能有氧操五式 }\end{array}$ & $\begin{array}{l}\text { 拜日式: 簡式、蛇式、繁 } \\
\text { 式、眼鏡蛇式 }\end{array}$ & $\begin{array}{l}\text { 背部強化操五式、腹部功能 } \\
\text { 操四式、䬨式、兔式或蛙式 }\end{array}$ & $\begin{array}{l}\text { 下背伸展操五式、 } \\
\text { 大休息式 }\end{array}$ \\
\hline 7 & $\begin{array}{l}\text { 氣功暖身十式、功 } \\
\text { 能有氧操五式 }\end{array}$ & $\begin{array}{l}\text { 站立三角式 : 大側角伸展 } \\
\text { 式、三角支摚式 (屈腿、 } \\
\text { 伸腿) +扭轉各式 }\end{array}$ & $\begin{array}{l}\text { 背部強化操五式、腹部功能 } \\
\text { 操四式橋式脊椎操、蛙式 }\end{array}$ & $\begin{array}{l}\text { 下背伸展操五式 } \\
\text { 大休息式 }\end{array}$ \\
\hline 8 & $\begin{array}{l}\text { 氣功暖身十式、功 } \\
\text { 能有氧操五式 }\end{array}$ & $\begin{array}{l}\text { 擴胸伸背式、連續犬式脊 } \\
\text { 椎操＋支撑扭轉各式 }\end{array}$ & $\begin{array}{l}\text { 背部強化操五式、腹部功能 } \\
\text { 操四式、弓式、蛙式 }\end{array}$ & $\begin{array}{l}\text { 下背伸展操五式、 } \\
\text { 大休息式 }\end{array}$ \\
\hline 9 & $\begin{array}{l}\text { 氣功暖身十式、功 } \\
\text { 能有氧操五式 }\end{array}$ & $\begin{array}{l}\text { 站立平衡式 : 基本站姿平 } \\
\text { 衡各式、大樹式、鶴姿、 } \\
\text { 老鷹姿、星星姿、舞者姿 }\end{array}$ & $\begin{array}{l}\text { 背部強化操五式、腹部功能 } \\
\text { 操四式、輪式、蛙式 }\end{array}$ & $\begin{array}{l}\text { 下背伸展操五式、 } \\
\text { 大休息式 }\end{array}$ \\
\hline 10 & $\begin{array}{l}\text { 氣功暖身十式、功 } \\
\text { 能有氧操五式 }\end{array}$ & $\begin{array}{l}\text { 拜日式 : 簡式+繁式、蛇 } \\
\text { 式、眼鏡蛇式 }\end{array}$ & $\begin{array}{l}\text { 背部強化操五式、腹部功能 } \\
\text { 操四式、四點跍姿背部強化 } \\
\text { 操、球操 }\end{array}$ & $\begin{array}{l}\text { 下背伸展操五式、 } \\
\text { 大休息式 }\end{array}$ \\
\hline 11 & $\begin{array}{l}\text { 氣功暖身十式、功 } \\
\text { 能有氧操五式 }\end{array}$ & $\begin{array}{l}\text { 站立三角式 : 大側角伸展 } \\
\text { 式、三角支摚式 (屈腿、 } \\
\text { 伸腿) +扭轉各式、平衡 }\end{array}$ & $\begin{array}{l}\text { 背部強化操五式、腹部功能 } \\
\text { 操四式、四點喼姿背部強化 } \\
\text { 操 }\end{array}$ & $\begin{array}{l}\text { 下背伸展操五式、 } \\
\text { 大休息式 }\end{array}$ \\
\hline 12 & $\begin{array}{l}\text { 氣功暖身十式、功 } \\
\text { 能有氧操五式 }\end{array}$ & $\begin{array}{l}\text { 擴胸伸背式+平衡式、連 } \\
\text { 續犬式脊椎操＋支撑扭轉 } \\
\text { 各式 }\end{array}$ & $\begin{array}{l}\text { 背部強化操五式、腹部功能 } \\
\text { 操四式、四點跍姿背部強化 } \\
\text { 操 }\end{array}$ & $\begin{array}{l}\text { 下背伸展操五式、 } \\
\text { 大休息式 }\end{array}$ \\
\hline
\end{tabular}




\section{參、結果與討論}

\section{一、基碟生理值}

實驗期間受試者之安靜心跳率、收縮壓及舒張壓等 基礎生理值如表三，結果顯示：十二週的課程對收縮壓並 無影響, 但受試者的安静心跳率及舒張壓均顯著下降 $(\mathrm{p}<$ .05），平均降低幅度分別達 $4.66 \%$ 及 $10.51 \%$ 。此結果顯示社 區大學所開設的強力適能瑜珈課程可降低安靜心跳及舒張 壓, 此結果與菢碧鶴與黄清如 (2005) 的研究相近, 該作者 認為是強力適能瑜珈課程類似放鬆訓練而達到的效果。

表三 實驗期間基礎生理值之變化

\begin{tabular}{lll}
\hline 變項 & 課程前 & 課程後 \\
\hline $\begin{array}{c}\text { 安靜心跳率 } \\
\text { (beat/min) }\end{array}$ & $\mathbf{8 2 . 3 3 \pm 1 1 . 1 5}$ & $\mathbf{7 8 . 0 0 \pm 8 . 5 8 *}$ \\
$\begin{array}{l}\text { 收縮壓 } \\
(\mathrm{mm}-\mathrm{Hg})\end{array}$ & $115.87 \pm 15.96$ & $113.20 \pm 12.97$ \\
$\begin{array}{c}\text { 舒張壓 } \\
(\mathrm{mm}-\mathrm{Hg})\end{array}$ & $77.07 \pm 10.78$ & $68.27 \pm 8.81 *$ \\
\hline
\end{tabular}

*與課程前比較達顯著差異 $\mathrm{p}<.05$ 。

\section{二、體位值}

實驗期間受試者之體重、身體質量指數、去脂體重 (fat free mass)、體脂率、腰圍及慰圍如表四, 結果顯示： 12 週的課程後, 受試者之腰圍與慰圍均顯著變小, 腰慰比顯 著下降（ $\mathrm{p}<.05 ） ；$ 體重、去脂體重並沒有改變（ $\mathrm{p}>$.05）， 但有下降之芻勢, 而體脂率則顯著下降 $(\mathrm{p}<.05)$, 此結果 顯示本研究之強力適能瑜功課程能有效減少體脂肪。

陳金鼓（2000）以女性大學教職員為對象進行每週兩 次、每次 60 分鐘的瑜珈運動之研究, 則顯示 3 個月的哈達瑜 珈課程對腰圍並沒有改善的效果; 此外, 吕碧琴（1997）之 研究以 80 位大學女生為對象, 進行7週的瑜珈課程、而陳金 鼓與甘光熙（1997）的研究以大學生為對象, 進行11週的瑜 珈課程, 結果亦均指出哈達瑜珈並不能有效降低體脂肪。而 溫蕙甄等人 (2005) 及郎碧鶴與黃淨如（2005）的研究均顯 示強力適能瑜珈可降低身體質量指數, 鄒碧鶴與黃艎如的研 究則顯示強力適能瑜功對體脂率及腰慰圍比均無影響。探究 此結果之差異, 可能在於本研究單次主運動持續的時間 $(60$ 分鐘）較長, 更能持續燃燒脂肪而達到較佳之降低體脂肪及 腰慰比的效果; 未來若能鼓勵受試者每週至少至練習一次, 對體重控制、甚至去脂體重的增加應該會有更好的效果。

表四 實驗期間體位值之變化

\begin{tabular}{|c|c|c|c|c|c|}
\hline 變項 & 課程前 & & & 課程後 & \\
\hline 體重（kg） & 56.16 & \pm & 9.66 & $55.69 \pm$ & 8.38 \\
\hline 身體質量指數（kg/m2） & 21.57 & \pm & 3.47 & $21.35 \pm$ & 2.95 \\
\hline 去脂體重（kg） & 37.83 & \pm & 4.73 & $38.44 \pm$ & 4.73 \\
\hline 體脂率（\%） & 32.20 & \pm & 3.38 & $30.73 \pm$ & $2.94^{*}$ \\
\hline 腰圍 (cm) & 72.30 & \pm & 7.94 & $70.62 \pm$ & $7.01 *$ \\
\hline 慰圍（cm） & 93.81 & \pm & 6.76 & $93.21 \pm$ & $7.18 *$ \\
\hline 腰腎比 & 0.77 & \pm & 0.04 & $0.76 \pm$ & $0.03 *$ \\
\hline
\end{tabular}

*與課程前比較達顯著差異 $p<.05$ 。 


\section{三、肌肉及心肺適能}

實驗期間受試者之背肌力、1分鐘仰卧起坐與3分鐘登 階之檢測結果如表五, 結果顯示 : 社區大學 12 週的強力適 能瑜珈課程對背肌力及腹肌力均無影響。然而, 3分鐘登階

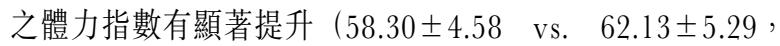
$\mathrm{p}<.05 ）$, 進步幅度達 $6.78 \%$ 。即本研究之強力適能瑜珈課程 對心肺適能有改善之效果，而對肌肉適能則無影響。
陳金鼓與甘光熙（1997）、陳金鼓（2000）、Dash \& Telles (2001) · Tran, Holly, Lashbrook, and Amsterdam (2001) 的研究均顯示哈達瑜珈可以改善肌力, 而溫德甄等人 （2005）及㱀碧鶴與黃淨如（2005）的研究則顯示強力適能 瑜珈能提升心肺耐力, 以及 1 分鐘屈滕仰卧起坐的能力。但 本研究結果顯示強力適能瑜珈在肌肉適能方面並無改善之效 果, 可能因本研究之課程每週僅進行一次, 並不足以達到肌 肉適能提升的效果。再者, 本研究的強力適能瑜珈課程較偏 向於靜態的動作, 此與溫蕙甄等人的研究中除了 30 分鐘的強 力適能瑜珈外, 另外加入了 20 分鐘的肌力訓練有所不同, 這 可能也是造成研究結果差異的原因。

\section{表五 實驗期間肌肉及心肺適能之變化}

\begin{tabular}{lllll}
\hline 變項 & 課程前 & \multicolumn{3}{l}{ 課程後 } \\
\hline 背肌力 $(\mathrm{kg})$ & $66.77 \pm$ & 14.19 & $68.68 \pm$ & 14.17 \\
1分鐘仰臥起坐 $(\mathrm{time})$ & $23.00 \pm$ & 6.77 & $23.80 \pm$ & 5.13 \\
& & & & \\
體力指數 & $58.30 \pm$ & 4.59 & $62.13 \pm$ & $5.29 *$ \\
\hline
\end{tabular}

*與課程前比較達顯著差異 $\mathrm{p}<.05$ 。

\section{肆、結論與建議}

本研究結果顯示台中市大墩社區大學所開設之的強力適 能揄珈課程（每週一次、每次 90 分鐘、持續12週）之介入能 有降低安靜心跳率、舒張壓、體脂率、腰圍、慰圍及腰慰比 的效果, 同時亦可提升心肺適能, 即社區大學的強力適能瑜 珈對基礎生理值、體位值及心肺適能都能有改善效果。

\section{參考文獻}

朱碧梧（2003）：強力適能瑜珈在大專體育教學的應用。大 專體育, $64,1-6$ 。

呂碧琴（1997）：瑜珈體位法對大學女生健康適能的影響效 果探討。臺大體育學報，1，233-254。

林貞岑（2003）：瑜伽-全球健康新風潮。康健雜誌，60， $105-110$ 。

洪睿聲、陳坤檸（2003）：瑜珈之生理心理功能。大專體 育, $69,147-155$ 。

陳金鼓、甘光熙（1997）：瑜珈對大學生基本體能之影響。 體育與運動, 104, 49-55。
然而, 因受開課之限制每週只進行一次, 並無法達到降 低身體質量指數與提升肌肉適能的效果, 建議未來開課的教 師能鼓勵並指導學員除了正式的課程外, 每週仍能自行練習 1 2次, 而對生理有更大的助益。

陳金鼓（2000）：瑜功訓練對靜態工作女性之健康體適能影 響。華岡理科學報，17，83-91。

陸文䫝、支藝樺（2001）。健康魔法書。台北：民視文化。

教育部（1997）：教師體適能指導手冊。台北：教育部。

溫蕙甄、蔡昆霖、陳雅慧、方進隆（2005）：十二週強力體 適能瑜功訓練對停經後婦女功能性體適能與骨質密度之 影響。運動教練科學, 5, 13-21。

㱀碧鶴、黃䇶如（2005）：比較適能瑜珈與體重控制運動處 方介入對大學生健康體適能的影響。嘉南學報, 31 , $405-419$ 。 
Bharshankar, J. R., Bharshankar, R. N., Deshpande, V. N., Kaore, S. B., \& Gosavi, G. B. (2003). Effect of yoga on cardiovascular system in subjects above 40 years. Indian Journal of Physiology and Pharmacology, 47 (2), 202-206.

Goldberg, B. (1997). Alternative Medicine: The Definitive Guide. Future Medicine Publishing: California, U.S.A. p.p. 469-480.

Innes, K. E., Bourguignon, C., \& Taylor, A. G. (2005). Risk indices associated with the insulin resistance syndrome, cardiovascular disease, and possible protection with yoga: a systematic review. The Journal of the American Board of Family Practice, 18(6), 491-519.

Madanmohan, Udupa, K., Bhavanani, A. B., Shatapathy, C. C., \& Sahai, A. (2004). Modulation of cardiovascular response to exercise by yoga training. Indian Journal of Physiology and Pharmacology, 48 (4), 461-465.

Tran, M. D., Holly, R. G., Lashbrook, J., \& Amsterdam, E. A. (2001). Effects of Hatha Yoga Practice on the Health-Related Aspects of Physical Fitness. Preventive Cardiology, 4 (4), 165-170.

\section{Correspondence:}

Chean-Chean Huang,

Department of Sport and Business Management, Da-Yeh University,

N0.112, Shanjiao Rd., Dacun, Changhua,

Taiwan 51591, R.O.C.

(彰化縣大村鄉山腳路112號)

E-mail : quenhuen@mail2000.com.tw

Telephone : +866-4-8511888 ext. 1323

Fax : $\quad$ +866-4-8511040 